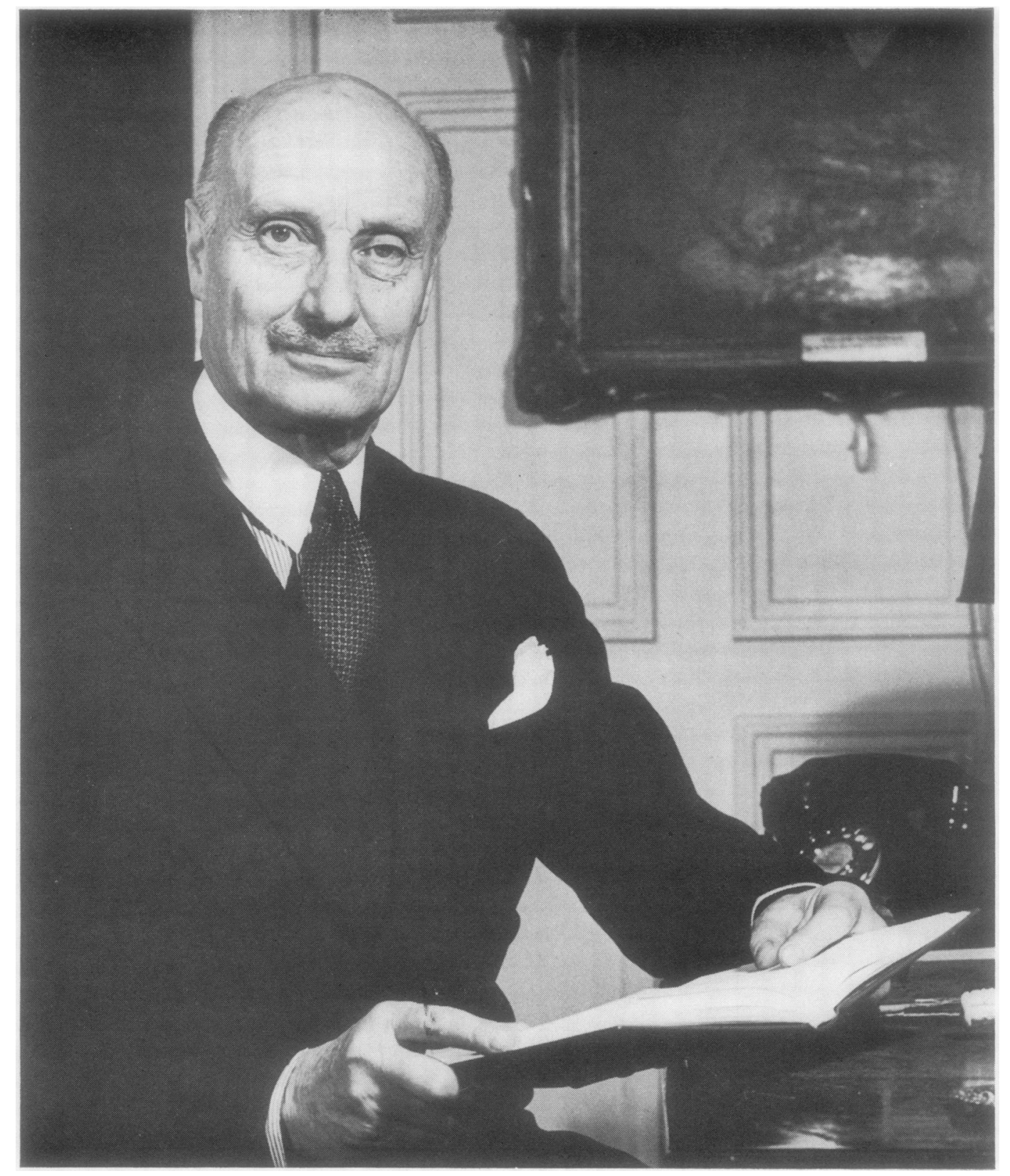

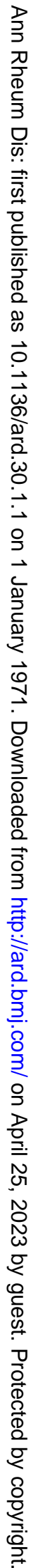




\section{The end of an era}

'When the Royal College of Physicians of London appointed their first special committee to survey the rheumatic diseases in 1933, this field of medicine was derelict. Since that time, academic interest in all branches of rheumatology has gradually become world-wide, and is rapidly increasing.'

So wrote W. S. C. Copeman in the preface to the Third Edition of his Textbook of the Rheumatic Diseases in 1964. He did not point out that this transformation had come about as the result, to a remarkable degree, of his own efforts, and of his clear-sighted determination to establish rheumatology as a scientific medical discipline. Today we mourn his passing, together with that of Professor Lenoch of Prague, another distinguished international figure, and tributes to these men will be found on other pages of this issue. The Annals of the Rheumatic Diseases, indeed, has suffered a special bereavement, for W. S. C. Copeman was closely associated with the foundation of the Journal in January, 1939 (when it began life as The Rheumatic Diseases*), and he watched its development thereafter, as a member of the Editorial Board and from 1954 as Editor, with personal pride, care, and affection.

The progress in prevention and treatment of the rheumatic diseases which took place during the lifetime of Copeman nevertheless emphasizes the deficiencies that remain. Some of these disorders, such as rheumatic fever and gout, now present minor therapeutic problems in this country compared with former times, but knowledge of the aetiology and treatment of others such as rheumatoid arthritis is still quite inadequate, although standards of management have undoubtedly improved greatly. The main body responsible for the financial support of research, the Arthritis and Rheumatism Council, and the principal forum for communication, the Heberden Society, occupy stronger positions than at any time in their history, but increasing attention is needed to ensure that resources remain adequate and that they are directed to their best advantage. Finally, although the overall quality of care for patients in the United Kingdom is high compared with that of many other countries, it has been shown that there are marked regional variations, some areas being very short of properly trained specialists. Related

\footnotetext{
*The foundation of the Journal in 1939 had been prectded by four 'Annual Reports' (1935-38) of the Special Committee on Chronic Rheumatic Diseases appointed by the Royal College of Physicians. The second issue (May, 1939) took the title Annals of the Rheumatic Diseases.
} 
to this is the whole question of the career structure in rheumatology, the designation of rheumatologists, and their limits of responsibility. These problems are now again under discussion owing to the necessity for specialist registration by the Royal Colleges, and although the arguments back and forth have become rather tedious by repetition, the matter must be thrashed out to a satisfactory conclusion, not only because it is of importance to the immediate well-being of patients but because it bears directly upon the recruitment, training, and subsequent careers of rheumatologists.

It is to be hoped that the memory of Copeman's achievements will remain a continued stimulus as they were during his life, and that those who follow may approach these undertakings collectively with the same attributes which he displayed as an individual-singleness of purpose without narrowmindedness, determination without arrogance, and dedication to the care of patients with rheumatic diseases in the various fields of clinical responsibility, research, education, and administration. If so, the work of this illustrious man will advance along the lines he would have wished, and the era which has seen the foundation and establishment of rheumatology will pass into one of fulfilment. 